\section{Debate: Why is everyone except me wrong about climate change policy?}

\section{Mark C. Freeman}

Add some subheadings?

This article aims to stimulate debate around publicly-expressed, opposed opinions, on climate change and to briefly explore the reasons that could drive these contrary views. The strong association between an individual's concern about the threat of climate change, and whether they more generally lie on the right or left of the political spectrum, has been extensively evidenced in the academic literature; see, for example, McCright et al. (2016) and the references therein. Results from a 2017 Gallup poll in June 2017 indicated that this partisan divide between Republicans and Democrats in the USA is growing ever wider. Compared to a decade earlier, there has been a rise of over 10 percentage points in Democrats who worry a great deal about climate change (66\% from 55\%), while this percentage for Republicans has fallen by six percentage points from an already much lower base (18\% from 24\%). This helps explain the Trump administration's position on the Paris Agreement.

In the highly heated exchanges in online forums, those on the political left often assign the unwillingness of 'climate deniers' to accept the urgency to act on reducing greenhouse gas emissions as evidence of narrow vested interests, stubbornness and general scientific stupidity. Similarly, those who make the strongest case for climate change action are disparaged as 'watermelons' (Delingpole, 2012)-green on the outside and red on the inside, where environmentalism is used as a stealth mechanism to action a socialist agenda via the back door.

While there is no doubt some truth in both these sets of accusations for a minority of people, they do not strike me as being helpful for a meaningful discussion on how to move forward the policy agenda. As Sun Tzu (explain) noted, 'If you know yourself but not the enemy, for every victory gained you will also suffer a defeat'. Ridiculing those who disagree with us cannot fully equate to understanding as, even among the expert community. Pindyck (2016) has documented large disagreements over how much should be spent to reduce carbon dioxide emissions. I therefore briefly propose a framework that combines moral foundation theory, rational learning, and differences in individual ethical preferences that I think will allow for improved discourse.

Moral foundation theory is beautifully explained in Haidt (2013). Its essence is that we have five moral taste-buds that are rooted deep within ourselves. These relate to caring; fairness; loyalty to the group; respect and authority; and sanctity. There is a clear association between the way we individually weight the importance of each of these issues, our political affiliations and our personality traits. In particular, the political left place very strong emphasis on caring and fairness at the expense of the last three, while the political right weight them more evenly. Because of the innate nature of our moral taste buds, our genetic makeup is strongly associated not only with our personality but also our political beliefs (for example Hatemi and McDermott, 2012; Verhulstet al., 2012). Within this framework, we do not form political arguments for our own benefit-our unconscious selves have broadly decided on the right answer to a political question long before our rational minds are awakened-but, instead, for the persuasion of others. Given the issues of caring and fairness both to poorer societies and future generations that are entailed in the climate change debate, it is unsurprising that the left/right divide on this matter has been linked to moral foundation theory (for example Markowitz and Shariff, 2012). While this may come as something of a shock to the rationalists, the chances are that you had, to a significant degree, determined your policy position on climate change long before you seriously assessed any evidence on the subject.

Of course, individuals should move from their initial stance as they update their views based on increasingly detailed scientific information. But the evidence on this is sketchy. For example, Kahan et al. (2012) finds no evidence that scientific illiteracy is greater among climate change sceptics but, instead, that knowledge increases polarization. Bolsen and Druckman (2016) also find increased polarization, but no evidence that any group is willing to pay more to prevent climate change, as they become more scientifically informed (see also Deryugina and Shurchkov, 2016). In a recent paper, I argue that this might be the consequence of purely rational behaviour 
(Freeman, 2017). As climate skeptics receive more information, their mean estimate of future climate change becomes greater, but they also become less concerned about potentially catastrophic outcomes. Greater knowledge reduces uncertainty, lowering the insurance premium that they are prepared to pay. Scientific communication alone does not, therefore, result in harmonization of policy positions. On the basis of this evidence, I conjecture that, however much research you have done on this topic, your policy views will have remained largely unchanged over time. It is rare indeed to find a climate skeptic who becomes a policy advocate, or vice versa, and we do not need explanations based on vested interests, stupidity or political stealth to explain this phenomenon.

Finally, we all take different ethical positions on a number of key issues that are relevant for the climate change debate; I highlight two here. First, the more impatient we are, the less prepared we will be to act to prevent damage to future generations - this would involve giving up consumption now for benefits in the far future that we are not readily prepared to wait for. More formally, 'impatience' refers to a higher utility discount rate. If this parameter value is high, then anticipated future utility gains from climate change mitigation are heavily discounted when calculating welfare. As a consequence, the present values of projects that reduce greenhouse gas emissions are low. Yet our impatience depends on a large number of features; not least our age (Read and Read, 2004) and gender (Dittrich and Leipold, 2014) and, indeed, can even be manipulated even for a given individual (Lempert and Phelps, 2016). In a recent survey, my co-authors and I found significant disagreement among discounting experts on how impatient a social planner should be when addressing long-term problems (Drupp et al., 2015).

Second, the value that individuals place on the environment itself varies enormously. For example, McCauley (2006, p. 27) presents the opinion that 'the aggregate value of a chunk of nature-its aesthetic beauty, cultural importance and evolutionary significance-is infinite', while others place much greater value on current human life. Given that many of these ethical differences are irreducible (Freeman and Groom, 2015), we cannot expect people to come to similar policy conclusions on this matter however much we debate with them. A further issue for discussion is the range of estimates of the effectiveness of different climate change preventative measures.
Given the strong influence our genetics and personality have on our political views and the strong correlation this has with the climate change debate, the apparent inability of scientific communication to bridge this policy divide, and irreducible differences over ethical matters concerning time and the value of the environment, disagreement over climate change policy is fundamentally inevitable. This leads me to the view that we should try to understand each other's positions better and engage in less name-calling before concluding that, in the end, I am the one who is right after all.

\section{References}

Bolsen, T. and Druckman, J. (2016), Partisan group identity and belief in human-caused climate change (Institute for Policy Research Working Paper WP-16-21).

Delingpole, J. (2012), Watermelons: How Environmentalists are Killing the Planet, Destroying the Economy and Stealing your Children's Future (Biteback Publishing).

Deryugina, T. and Shurchkov, O. (2016), The effect of information provision on public consensus about climate change. PLoS One, 11, 4, pp. 1-14.

Dittrich, M. and Leipold, K. (2014), Gender differences in time preferences. Economics Letters, 122, pp. 413-415.

Drupp, M. A., Freeman, M. C., Groom, G. and Nesje, F. (2015), Discounting disentangled: an expert survey on the determinants of the longterm social discount rate (Grantham Research Institute on Climate Change and the Environment: Working Paper No. 172).

Freeman, M. C. (2017), What is a rational policy response to pessimistic new evidence? (Working paper, University of York).

Freeman, M. C. and Groom, B. (2015), Positively gamma discounting: combining the opinions of experts on the social discount rate. Economic Journal, 125, pp. 1015-1024.

Haidt, J. (2013), The Righteous Mind (Penguin).

Hatemi, P. K, and McDermott. R. (2012), The genetics of politics: discovery, challenges, and progress. Trends in Genetics, 28, 10, pp. 525533.

Kahan, D. M. et al. (2012), The polarizing impact of science literacy and numeracy on perceived climate change risks. Nature Climate Change, 2, pp. 732-735.

Lempert, K. M. and Phelps, E. A. (2016), The malleability of intertemporal choice. Trends in Cognitive Science, 20, pp. 64-74.

Markowitz, E. M. and Shariff. A. F. (2012), Climate change and moral judgement. Nature Climate 
Change, 2, pp. 243-247.

McCauley, D. J. (2006), Selling out on nature. Nature, 443, 7107. pp. 27-28.

McCright, A. M., Dunlap, R. E. and MarquartPyatt, S. T. (2016), Political ideology and views about climate change in the European Union. Environmental Politics, 25, pp. 338-358.

Pindyck, R. S. (2016), The Social Cost of Carbon Revisited (NBER).

Read, D. and Read, N. L. (2004), Time discounting over the lifespan. Organizational Behavior and Human Decision Processes, 94, pp. 22-32,

Verhulst, B., Eaves, L. J. and Hatemi, P. K. (2012), Correlation not causation: the relationship between personality traits and political ideologies. American Journal of Political Science, 56, pp. 34-51.

Mark C. Freeman is XXX, York Management School, University of York, UK.

\section{Debate: Too close for comfort- regulation and governance of the UK's nuclear industry and implications for inter-generational equity?}

\section{Barry Pemberton and Wilson Ng*}

Nuclear technologies create a number of potential inter-generational equity problems that require effective governance (Pemberton, 2016). This article raises a number of concerns with the regulation, governance and accountability practices associated with nuclear power production. Can this problem be resolved with incremental reforms or is fundamental governance restructuring required?

On 28 December 2016, The Times ran an

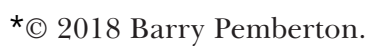

article suggesting that the UK Office for Nuclear Regulation (ONR) had become 'too close to the industry to police it' (Moody, 2016). The background to this article includes concerns over accidents considered to be 'of no nuclear safety significance' (ibid.), although those accidents included workers' exposure to radioactive material. The ONR was established as a statutory public corporation under the Energy Act 2013 to regulate the nuclear industry (ONR, 2016) and reports to the Department for Work and Pensions. Its predecessor was the Nuclear Installations Inspectorate (NII) and the ONR continues the NII's close relationship with government.

The issue of problematic regulators is gaining importance given current developments within the UK nuclear industry, its track record and implications for intergenerational equity. This article identifies three issues that frame the challenges associated with the future governance and accountability of the UK's nuclear industry.

\section{Three issues of (mis-)governance}

Poor transparency

Our first concern is the poor transparency of the UK's nuclear industry. The industry has been in a period of decline, which began with its privatization in the late 1990s. Sizewell B, the last reactor built, entered service in 1995 and, together with ageing gas-cooled reactors, forms the remnants of a once-prized industry, now owned by the French company EDF. However, even Sizewell B is expected to close by 2035 (WNA 2016).

Given this decline, the industry has a serious environmental legacy relating to redundant hazardous sites and nuclear waste with significant inter-generational impacts (Secretary of State for Trade and Industry, 2002). Further, the nuclear industry is characterized by a lack of public accountability attributed to an endemic culture of secrecy arising from the industry's military work (Williams, 1980). Despite apparently being heavily regulated, strategic decisions received insufficient public scrutiny and public funds were mis-allocated (Durie and Edwards, 1982). This has led to the UK's nuclear policy being described as the 'most expensive failure of post-war British policy-making' (Huhne, 2011). Announcements of a possible nuclear renaissance, manifest in the planned reactor at Hinkley Point, raise further concerns relating to accountability, governance and regulatory issues, particularly given the risks associated with foreign investment in a UK nuclear plant. 
Sustainability concerns

The environmental and economic sustainability of the nuclear industry has been persistently questioned. In 1996 the industry was restructured by splitting it into sites deemed commercially viable and legacy sites that required public subsidies. This restructuring required the government to undertake a 'complex capital restructuring and relisting in 2005' (Jupe, 2012, p. 125), which effectively created an uncapped liability for these 'commercially viable' sites to be funded by UK taxpayers (McKerron, 2012). The legacy sites and nuclear waste retained in public ownership have no credible source of funding for legacy sites' liabilities, despite the existence of a government-approved three-year plan (NDA, 2008; 2016). The Nuclear Decommissioning Authority (NDA), who own these legacy sites, noted that the efficacy of this funding arrangement is 'largely attributable to factors over which it has limited or no control' (NDA, 2008 , p. 43). Therefore, liabilities, held in the public or private sector, will require undetermined levels of funding by taxpayers. Yet, management control over legacy sites have been heavily criticised (PAC, 2013; 2014; 2015). Recent figures suggest that publicly-held liabilities are estimated as $£ 161$ billion, which is a 30\% increase since 2003 (NDA, 2016, p. 11).

Inter-generational equity and the nuclear legacy The long-lived and toxic nature of the nuclear industry's legacy creates the need for a unique approach to resolve its problems, for example the disposal and treatment of nuclear waste. Forty years ago, a Royal Commission on Environmental Pollution advised the UK government to resolve the inter-generational problem of nuclear waste. A subsequent report on nuclear power and the environment (Flowers, 1976) advised that there should be no commitment to a nuclear power programme until the government had demonstrated 'the safe containment of highly radioactive waste for the indefinite future' (Blowers and Pepper, 1987, p. 141). Nevertheless, the UK still does not have any solutions for the disposal of the waste from nuclear sites, leaving a legacy for future generations.

\section{Questions for debate}

Questions urgently in need of further research are:

- Given claims that the government's poor governance and decision-making was attributed to lack of transparency and poor public accountability, what accounting and accountability reforms are required of the regulators and those responsible for the governance of nuclear sites?

- The financial and environmental hazards associated with nuclear technologies are significant. The inter-generational equity associated with the industry's legacy costs remain incalculable but will fall upon future generations. What governance systems are considered appropriate for the nuclear industry in order to assure the sustainability of current and future liabilities?

-The unresolved and potentially catastrophic hazards of nuclear waste may seriously affect the health and natural environment of UK citizens far into the foreseeable future. What accountability and governance solutions are required to deal with these social and environmental hazards?

UK regulations introduced over 60 years ago are clearly in urgent need of fundamental reform. The current situation is problematic in that a highly toxic unaccountable industry, which creates incalculable, unfunded liabilities to be paid by future taxpayers, appears to be neither governed nor regulated effectively.

\section{References}

Blowers, A. and Pepper, D. (1987), Nuclear Power in Crisis (Weidenfeld \& Nicolson).

Durie, S. and Edwards, R. (1982), Fuelling the Nuclear Arms Race (Pluto Press).

Flowers, B. (1976), Royal Commission, Sixth Report: Nuclear Power and the Environment. Cmnd 6618.

Huhne, C. (2011), Why the future of nuclear power will be different. Speech to the Royal Society (13 October).

Jupe, R. (2012), The privatization of British Energy: hazards transfer and the state. Accounting, Organizations and Society, 37, 2, pp. 116-129.

McKerron, G. (2012), Evaluation of Nuclear Decommissioning and Waste Management (SPRU).

Moody, O. (2016), Nuclear safety watchdog under review after series of accidents. The Times (28 December).

NDA (2008), Annual Plan 2007-8.

NDA (2016), Annual Report and Accounts 201516, HC 405.

ONR (2016), DWP/ONR Framework Document.

PAC (2013), Sellafield Follow Up (Part 2). HC 708.

PAC (2014), Progress at Sellafield. 43rd Report.

PAC (2015), Progress on the Sellafield Site: An Update.

Pemberton, B. (2016), Corporate Governance and 
the Nuclear Industry (Routledge).

Secretary of State for Trade and Industry (2002), Managing the Nuclear Legacy, Cm 552 (HMSO). Williams, R. (1980). The Nuclear Power Decisions: British Policies 1953-78 (Croom Helm).

WNA (2016), Nuclear Power in the UK (www.worldnuclear.org).

Barry Pemberton is a researcher into governmentrelated issues.

Wilson Ng is XX, University of Roehampton, UK.

\section{Debate: Integrated reporting and accounting for sustainable development across generations by universities}

\section{Carol A. Adams}

This article aims to stimulate debate on how integrated thinking and reporting can contribute to value creation for university stakeholders and help to achieve the UN's sustainable development goals (SDGs). Universities have significant influence over a large proportion of the world's future leaders. Reporting, managing, engaging and developing strategy on sustainable development issues therefore stands to have considerable impact. Similarly, the way students are educated can be a force for change (see Adams et al., 2011). Universities thus had the potential to make one of the biggest impacts of any sector through sustainability reporting and stand to be among the biggest beneficiaries of integrated thinking and integrated reporting.

Yet despite 20 years of developments in sustainability reporting and more than five in integrated reporting, the annual reporting packages of universities have barely changed. They are largely unimaginative and backwardlooking consisting of compliance disclosures, financial statements and explication of governance structures and management teams with some unverifiable 'feel good' information thrown in.

Universities have largely ignored global, cross-sectoral, multi-stakeholder developments in accounting for sustainability. Further, in contrast to efforts to develop integrated thinking' in the corporate world (Adams, 2017a), university structures and strategies continue to reflect functional and discipline silos (notwithstanding some admirable attempts to develop interdisciplinary research) and a separation of the academic from the operational. In making this statement I draw on over two decades of experience involving: cross-sectoral research in sustainability accounting and management processes and judging sustainability reports for awards; working with a number of standard- and guideline-setters to develop reporting on sustainable development issues; working as a professor and senior manager in universities; developing award-winning sustainability reports and management systems in a university; and, advising on integrated reporting and sustainability disclosures in other sectors.

The benefit to a university (and its stakeholders) of working out how it creates value and for whom (i.e. developing the value creation statement of an integrated report) is incalculable. The resulting statement would resonate much more than the bland and undifferentiated vision and mission statements (often involving mention of a higher position in rankings) which populate university websites.

Universities depend on financing from students (and their parents and/or the community), governments, industry and alumni, but they do not set out their 'business model' for making a contribution to the economic, social and environmental welfare of these providers of finance in a systematic way. Few university reports consider how their business model draws on and transforms multiple capitals (people, buildings, natural resources, relationships with stakeholders, systems and processes as well as finance) to create value.

As a result, the value a university creates through relationships with various stakeholders (including students, professional and government bodies, for example), the education it provides and its research is perhaps not considered in a systematic or holistic way when developing strategy. (See Adams, 2017a on the role reporting and board/council involvement in reporting play in influencing thinking and action.) Indeed, university engagement with stakeholders tends to be ad hoc, unsystematic 
and decentralized, thus raising questions as to its ability to pick up material 'external environment' risks and opportunities for incorporation into strategy. This is in part inferred from the lack of reporting to or identification of key stakeholders, how the universities engage with them and what their material issues are. Such disclosure is a feature of corporate sustainability and integrated reports.

Disclosure of a forward-looking strategy which considers economic, social and environmental risks and opportunities drives better strategic thinking and more value creation-and integrated reporting provides a framework for doing this. In a university, this might reasonably be expected to cover the provision of education and encouragement of research which addresses the risks and opportunities arising from a climate changed world with all the issues (such as energy, water and food security; increased poverty; inequality; refugee populations) that brings. After all, these changes will impact on every person, every job and every industry. Engagement between academic and operational staff on the quest to create value, as broadly defined and with reference to key stakeholders, can result in innovative collaborations and student projects which enhance operational outcomes.

The university sector has come under fire in recent years from national governments for lack of real impact (as distinct from measures of citation which, in any case, reflect that a large proportion of published research is not influential) of much of research. A value creation statement ought to curb the folly of university obsession with journal rankings which, certainly in accounting, can privilege North American accounting journals many of which rarely publish work outside their jurisdiction. Such rankings fail to adjust for the fact these journals can accrue higher citations because North America has a large proportion of accounting academics that research and use prior research work conducted in their own country. These journals have displayed (through their contents pages) a reluctance to publish innovative qualitative research, for example addressing accounting for sustainable development, and developing new theorizing and concepts to explain contemporary developments which can inform business school education. This issue has even received attention from the Prince of Wales and his Accounting for Sustainability charity (accountingforsustainability.org). Emphasising the extent of the problem, an email received in October 2017 from one publisher highlighted that $50 \%$ of articles published were included in the CiteScore, which calculates the citations from all documents in a particular year to all documents published in the previous three years for a particular journal. This means that as well as not having any real impact, much published research is not even influencing other researchers.

The situation has resulted in governments implementing means of assessing and rewarding research which makes a difference to practice and policy. A particular impetus for change comes from governments around the world committing to 17 SDGs. Universities are central to achievement of all 17 goals and governments may hold them accountable for making a contribution. Adams (2017b) provides practical guidance on how contribution to the SDGs can be aligned with strategy to create value.

If universities can figure out how they create value, and develop strategies which reflect dependence on multiple capitals and a systematic approach to identifying broader risks and opportunities, they might stave off government intervention in their affairs and reduce reliance on flawed approaches to ranking. In the $\mathrm{UK}$, the British Universities Finance Directors Group (BUFDG, 2016; 2017) and the Leadership Foundation for Higher Education are hoping to guide universities in this endeavour. The challenge for the sector will be not to assume universities need a special set of guidelines as has occurred with sustainability reporting, to the detriment of quality and quantity.

\section{References}

Adams, C. A. et al. (2011), The development of leaders able to respond to climate change and sustainability challenges: the role of business schools Sustainability Accounting, Management and Policy Journal, 2 , 1, pp. 165-171.

Adams, C. A. (2017a), Conceptualising the contemporary corporate value creation process. Accounting Auditing and Accountability Journal, 30 , 4, pp. 906-931.

Adams, C.A. (2017b), The Sustainable Development Goals, Integrated Thinking and the Integrated Report (IIRC and ICAS).

BUFDG (2016), Integrated Reporting in HE: Helping Universities Tell their Stories Better (www.efficiencyexchange.ac.uk).

BUFDG (2017), Integrated Reporting in Four British Universities (www.bufdg.ac.uk).

Carol A. Adams is Professor of Accounting at Durham University Business School, UK. 